\title{
Anxiolysis for laceration repair in children: a survey of pediatric emergency providers in Canada
}

\author{
Kriti Kumar $^{1} \cdot$ Samina Ali $^{2} \cdot$ Vikram Sabhaney $^{3} \cdot$ Evelyne Trottier $^{4} \cdot$ Amy Drendel $^{5} \cdot$ Maala Bhatt $^{6} \cdot$ Leslie Boisvert $^{1}$. \\ Naveen Poonai ${ }^{7,8}$ on behalf of Pediatric Emergency Research Canada
}

Received: 22 June 2021 / Accepted: 24 September 2021 / Published online: 8 November 2021

(c) The Author(s), under exclusive licence to Canadian Association of Emergency Physicians (CAEP)/ Association Canadienne de Médecine d'Urgence (ACMU) 2021

\begin{abstract}
Objectives Intranasal dexmedetomidine is a potentially effective anxiolytic but its role in pediatric laceration repair is only emerging. Future trials and clinical adoption of intranasal dexmedetomidine depend on understanding pediatric emergency providers' practice patterns surrounding anxiolysis and perceived barriers to intranasal dexmedetomidine for anxiolysis during suture repair in children. Our objectives were to characterize these parameters to inform future research and facilitate clinical adoption.

Methods We conducted an online survey of pediatric emergency physician members of Pediatric Emergency Research Canada from September to December 2020. Questions pertained to perceptions of anxiolysis for suture repair, with a focus on intranasal dexmedetomidine. The primary outcome was anxiolysis for suture repair. Data were reported using descriptive statistics.

Results The response rate was 155/225 (68.9\%). During suture repair, $127 / 148(86 \%)$ believed that $>25 \%$ of young children experience distress requiring physical restraint. 116/148 (78\%) would provide anxiolysis, mainly intranasal benzodiazepines (100/148, 68\%). Only 6/148 (4\%) would provide intranasal dexmedetomidine but 95/148 (64\%) would consider it if there was evidence of benefit. The most common perceived barriers to intranasal dexmedetomidine included inadequate personal experience $(114 / 145,79 \%)$ and lack of access $(60 / 145,41 \%)$.

Conclusions Most Canadian pediatric emergency providers believe that laceration repair in a young child is distressing. Despite questionable efficacy, most would provide intranasal benzodiazepines, but would consider intranasal dexmedetomidine if there was evidence of benefit.
\end{abstract}

Keywords Laceration repair · Anxiolysis · Pediatrics · Procedural distress · Emergency department · Sedation · Dexmedetomidine

\section{Résumé}

Objectifs La dexmédétomidine intranasale est un anxiolytique potentiellement efficace mais son rôle dans la réparation des lacérations en pédiatrie n'est qu'émergent. Les futurs essais et l'adoption clinique de la dexmédétomidine intranasale dépendent de la compréhension des habitudes de pratique des urgentistes pédiatriques en matière d'anxiolyse et des obstacles perçus à la dexmédétomidine intranasale pour l'anxiolyse pendant la réparation des sutures chez les enfants. Nos objectifs étaient de caractériser ces paramètres pour éclairer les recherches futures et faciliter l'adoption clinique.

Prior presentations: Society of Academic Emergency Medicine (2021); Canadian Paediatric Society (2021); Pediatric Academic Societies (2021); Canadian Association of Emergency Physicians (2021)

Naveen Poonai

naveen.poonai@lhsc.on.ca

Extended author information available on the last page of the article 
Méthodes Nous avons mené un sondage en ligne auprès des médecins urgentistes pédiatriques membres de Recherche en urgence pédiatrique Canada (Pediatric Emergency Research Canada) de septembre à décembre 2020. Les questions portaient sur les perceptions de l'anxiolyse pour la réparation des sutures, en mettant l'accent sur la dexmédétomidine intranasale. Le résultat principal était l'anxiolyse pour la réparation des sutures. Les données ont été rapportées à l'aide de statistiques descriptives.

Résultats Le taux de réponse était de 155/225 (68,9\%). Pendant la suture, 127/148 (86\%) ont estimé que > $25 \%$ des jeunes enfants éprouvent une détresse nécessitant une contention physique. 116/148 (78\%) fourniraient une anxiolyse, principalement des benzodiazépines intranasales $(100 / 148,68 \%)$. Seulement $6 / 148(4 \%)$ fourniraient de la dexmédétomidine intranasale, mais 95/148 (64\%) l'envisageraient s'il y avait une preuve de bénéfice. Les obstacles les plus fréquemment perçus à la dexmédétomidine intranasale étaient une expérience personnelle insuffisante $(114 / 145,79 \%)$ et un manque d'accès (60/145, $41 \%)$.

Conclusions La plupart des fournisseurs canadiens de services d'urgence pédiatriques croient que la réparation des lacérations chez un jeune enfant est pénible. En dépit d'une efficacité douteuse, la plupart d'entre eux fourniraient des benzodiazépines intranasales, mais envisageraient la dexmédétomidine intranasale s'il était prouvé qu'elle était bénéfique.

\section{Clinician's capsule}

\section{What is known about the topic?}

Suture repair of lacerations is distressing for young children and intranasal benzodiazepines have not been shown to be consistently effective.

\section{What did this study ask?}

What are pediatric emergency clinicians' perceptions surrounding anxiolysis for suture repair of lacerations in children?

\section{What did this study find?}

Most pediatric emergency clinicians (68\%) would use intranasal benzodiazepines rather than dexmedetomidine, citing lack of experience and access as barriers.

\section{Why does this study matter to clinicians?}

Adoption of newer agents, such as intranasal dexmedetomidine will depend on quality evidence, improved knowledge, and minimizing delays in management.

\section{Introduction}

Laceration repair accounts for almost half of procedures performed in the emergency department (ED) [1]. Although lidocaine-epinephrine-tetracaine is commonly used in children, behavioral distress remains common [2]. Societal bodies have recommended a combination of physical, psychological, and pharmacological approaches to reduce pain and distress for children undergoing brief diagnostic and therapeutic procedures [3, 4]. Managing behavioral distress with mild sedatives may reduce the need to physically restrain children to minimize movement, a tactic that has been discouraged by the Canadian Paediatric Society [3].

Intranasal midazolam is the most commonly used agent for procedural distress in children for laceration repair [5].
However, evidence of benefit is inconsistent [6-8] and its administration is poorly tolerated because it is noxious to the nasal mucosa [9]. Other agents such as inhaled nitrous oxide have shown benefit [10], but require a cooperative patient and a gas scavenging system. Nitrous oxide may also be challenging to use for certain facial lacerations. Dexmedetomidine is a selective alpha- 2 receptor agonist that has been increasingly studied in children [11] likely due to its minimal deleterious cardiovascular and respiratory effects [11]. Intranasal dexmedetomidine (dexmedetomidine) is well tolerated and reportedly more effective than intranasal or oral midazolam in children undergoing intravenous insertion [12, 13] and dental procedures [14]. For laceration repair in children, a single study showed superior anxiolysis compared to intranasal midazolam, albeit only to facilitate initial positioning [2]. Exploring whether dexmedetomidine is superior to midazolam requires an understanding of providers' perceptions of the need for anxiolysis and perceived barriers to clinical adoption of dexmedetomidine.

With the growing interest in dexmedetomidine for children [6], our objectives were to characterize pediatric emergency clinicians' perceptions surrounding anxiolysis for suture repair of lacerations in children. Our findings may help inform the design of future trials of dexmedetomidine and facilitate clinical adoption of this agent.

\section{Methods}

\section{Study design and participants}

This was an online survey that included all independently practicing Canadian pediatric emergency physicians registered in the Pediatric Emergency Research Canada (PERC) database as of September 2020. PERC is a network of healthcare providers whose primary clinical, administrative, 
and academic appointments are within Canadian tertiary care pediatric EDs.

\section{Protocol}

Potential respondents were contacted via email from October 1 to December 30, 2020. A Modified Dillman Tailored Design Method was used to optimize responses [15]. A pre-notification email was sent on day 0 , followed by initial electronic survey dissemination on week 1 , and subsequent dissemination on week 2 , week 3 , week 7 and week 9 (non-responders only). The survey was administered using Research Electronic Data Capture (REDCap) [16]. Consent to participate was implied by completion of any portion of the survey. Respondents were offered a $\$ 5$ Starbucks card. To prevent duplicate entries, email addresses were assigned unique ID numbers in REDCap and corresponding surveys could be completed only once. The study received approval from Western University's Health Sciences Research Ethics Board.

\section{Instrument}

The survey was available in both English and French (Supplementary Appendix). It included demographic questions and a vignette depicting a 3-year-old male with a $3 \mathrm{~cm}$ forehead laceration requiring suture repair. Related to the vignette, respondents were asked: (i) whether they would offer analgesia and anxiolysis, (ii) type of analgesic and anxiolytic, (iii) perceptions surrounding analgesia and anxiolysis, (iv) degree to which analgesia and anxiolysis improved patient experience using a $100 \mathrm{~mm}$ Visual Analog Scale (VAS) from $0=$ "does not improve" to $100=$ "very much improves", and (v) experience with and perceptions surrounding intranasal dexmedetomidine to facilitate laceration repair. Response options were in the form of multiple choice, sliding scales, and free text. Free-text data were coded independently by two co-investigators (KK, NP). Survey respondents were permitted to edit and skip questions.

The survey was developed using the approach outlined by Burns et al. [17] using a five-member focus group, expert opinion, and literature review. To ensure content validity, a table of specifications was created to ensure each question fell into at least one domain of interest and each domain contained a sufficient number of items. Focus group members then ranked the questions by relevance to the research question. The survey was translated into French and checked for domains of equivalence (conceptual, item, semantic, operational, and measurement). Finally, the survey was piloted among three pediatric ED physicians who rated each question using a 5-item Likert scale for face validity, clarity, length, comprehensiveness, and bias.

\section{Statistical analysis}

All surveys were analyzed whether completed or not. The primary outcome was the proportion of respondents who would administer anxiolysis for suture repair of the laceration depicted in the vignette. Secondary outcomes included perceived barriers to dexmedetomidine, types of anxiolytic strategies, and perceptions of anxiolysis. Categorical data were summarized using percentages and frequencies. Continuous data were summarized using means and standard deviations (SD). Data were analyzed using Excel (version 16.5, Microsoft).

\section{Results}

\section{Respondents}

The response rate was 155/225 (68.9\%). Demographic data are summarized in Table 1.

\section{Analgesia}

In the context of the vignette, 152/152 (100\%) of respondents indicated they would provide analgesia. Topical anesthetic gels and subcutaneous local anesthetics were reported by $148 / 151(98.0 \%)$ and $74 / 151(49.0 \%)$ of respondents, respectively (Table 2$)$. In general, respondents $(n=148)$ believed that analgesia improved patient care experience to large degree, with a mean of $93 \mathrm{~mm}(\mathrm{SD}=11)$ on the VAS.

\section{Anxiolysis}

$116 / 148$ (78\%) of respondents stated they would provide anxiolysis or sedation for the child in the vignette. Most [100/148 (68\%)] endorsed intranasal benzodiazepines, with nitrous oxide and intravenous ketamine endorsed by $27 / 148$ (18\%) and 21/148 (14\%), respectively. Only 4/148 (3\%) endorsed dexmedetomidine (Table 3).

Respondents generally believed that anxiolysis improved the patient care experience to a large degree, with a mean of $83 \mathrm{~mm}(\mathrm{SD}=20)$ on the VAS. $127 / 148(86 \%)$ reported that greater than $25 \%$ of children experienced distress significant enough to require physical restraint during laceration repair. $101 / 145(70 \%)$ and $89 / 145(61 \%)$ believed that a caregiver or certified child life specialist, respectively, was usually insufficient to alleviate distress. 114/144 (79\%) disagreed that "laceration repair using sutures would not cause significant enough distress to warrant anxiolysis". The most common barriers to providing anxiolysis, where respondents indicated "somewhat" or "strong agreement", included delayed discharge $(72 / 147,49 \%)$ and management $(56 / 147$, $38 \%$ ) (Table 4). The most common perceived benefits of 
Table 1 Demographic characteristics of respondents

\begin{tabular}{|c|c|}
\hline Demographic characteristic & $n(\%)$ \\
\hline \multicolumn{2}{|l|}{ Level of certification $(n=141)$} \\
\hline Royal College/Board Certified/Board Eligible pediatric emergency medicine & $98(70)$ \\
\hline Royal College/Board Certified/Board Eligible emergency medicine & $17(12)$ \\
\hline Family medicine & $3(2)$ \\
\hline General Pediatrics & $16(11)$ \\
\hline Canadian College of Family Physicians_-Emergency Medicine & $6(4)$ \\
\hline American Board of Pediatrics-Pediatric Emergency Medicine & $1(0.7)$ \\
\hline \multicolumn{2}{|l|}{ Type of ED $(n=144)$} \\
\hline Pediatric-only emergency department & $135(94)$ \\
\hline General (adult and paediatric) tertiary care emergency department & $13(9)$ \\
\hline General (adult and pediatric) community emergency department & $5(3)$ \\
\hline General (adult and pediatric) urgent care clinic & $4(3)$ \\
\hline \multicolumn{2}{|c|}{$\begin{array}{l}\text { Pediatric patients treated (less than } 19 \text { years of age) out of the patient population that participants rou- } \\
\text { tinely treated }(n=147)\end{array}$} \\
\hline Less than $20 \%$ & $3(2)$ \\
\hline $21-40 \%$ & $9(6)$ \\
\hline $41-60 \%$ & $5(3)$ \\
\hline $61-80 \%$ & $1(0.7)$ \\
\hline $80-100 \%$ & $129(88)$ \\
\hline \multicolumn{2}{|l|}{ Years of experience as attending physician $(n=146)$} \\
\hline$>20$ years & $39(27)$ \\
\hline $16-20$ years & $24(16)$ \\
\hline $11-15$ years & $30(21)$ \\
\hline $6-10$ years & $30(21)$ \\
\hline Up to 5 years & $23(16)$ \\
\hline \multicolumn{2}{|l|}{ Gender $(n=146)$} \\
\hline Female & $78(53)$ \\
\hline Male & $66(45)$ \\
\hline Prefer not to answer & $2(1)$ \\
\hline \multicolumn{2}{|l|}{ Number of laceration repairs performed/month $(n=146)$} \\
\hline $1-3$ & $20(14)$ \\
\hline $4-6$ & $39(27)$ \\
\hline $7-10$ & $38(26)$ \\
\hline More than 10 & $49(34)$ \\
\hline I never perform laceration repairs & $0(0)$ \\
\hline \multicolumn{2}{|l|}{ Province of Practice $(n=146)$} \\
\hline Alberta & $24(16)$ \\
\hline Ontario & $53(36)$ \\
\hline Quebec & $33(23)$ \\
\hline Manitoba & $7(5)$ \\
\hline British Columbia & $9(6)$ \\
\hline Nova Scotia & $9(6)$ \\
\hline Newfoundland and Labrador & $5(3)$ \\
\hline Saskatchewan & $6(4)$ \\
\hline New Brunswick & $0(0)$ \\
\hline Northwest Territories & $0(0)$ \\
\hline Nunavut & $0(0)$ \\
\hline Yukon & $0(0)$ \\
\hline Prince Edward Island & $0(0)$ \\
\hline
\end{tabular}


Table 2 Practice patterns surrounding analgesia for laceration repair in the 3 -yearold male featured in the vignette $(n=148)$

\begin{tabular}{ll}
\hline Analgesic choices & $n(\%)$ \\
\hline Local anesthetics & $148(100)$ \\
Topical anesthetic gel (e.g., lidocaine-epinephrine-tetracaine or LET) & $74(50)$ \\
Subcutaneous/injected local anesthetic (e.g., lidocaine, bupivacaine) & $2(1)$ \\
Regional anesthesia (e.g., nerve block) & $4(3)$ \\
Topical anesthetic cream (e.g., EMLA ${ }^{\mathrm{TM}}$, Ametop \\
Oral analgesics & \\
Oral noxilene-opioid analgesic (e.g., acetaminophen and/or ibuprofen) & $63(44)$ \\
Oral ketorolac & $0(0)$ \\
Oral opioid analgesic & $0(0)$ \\
Intravenous analgesics & $2(1)$ \\
Intravenous non-opioid analgesic (e.g., ketorolac) & $0(0)$ \\
Intravenous opioid analgesic (e.g., morphine, fentanyl) & $9(6)$ \\
Intravenous ketamine & \\
Intranasal analgesics & $43(29)$ \\
Intranasal opioid analgesic (e.g., fentanyl) & \\
\hline
\end{tabular}

EMLA eutectic mixture of local anesthetics
Table 3 Practice patterns surrounding anxiolysis for laceration repair in the 3-year-old male featured in the vignette $(n=148)$

\begin{tabular}{ll}
\hline Anxiolytic choices & $n(\%)$ \\
\hline Oral & \\
Benzodiazepine (e.g., midazolam) & $9(6)$ \\
Dexmedetomidine & $0(0)$ \\
Intranasal anxiolytics & \\
Intranasal benzodiazepine & $100(68)$ \\
Intranasal dexmedetomidine & $4(3)$ \\
Intranasal ketamine & $8(5)$ \\
Intranasal fentanyl & $1(0.7)$ \\
Inhaled anxiolytics & \\
Inhaled nitrous oxide & $27(18)$ \\
Inhaled methoxyflurane & $1(0.7)$ \\
Intravenous & \\
Ketamine & $21(14)$ \\
Benzodiazepine (e.g., midazolam) & $1(0.7)$ \\
Propofol & $4(3)$ \\
\hline
\end{tabular}

anxiolysis included improved patient $(127 / 148,86 \%)$ and caregiver $(132 / 148,89 \%)$ satisfaction, a more cooperative child with future medical procedures $(121 / 148,82 \%)$, and improved provider morale and satisfaction $(111 / 148,75 \%)$.

\section{Intranasal dexmedetomidine}

Most respondents had limited experience with dexmedetomidine, with 90/146 (62\%) never having witnessed its use in any practice setting. The mean comfort level with dexmedetomidine by any route was $22 \mathrm{~mm}(\mathrm{SD}=28)$ on the VAS $(n=146)$. However, $95 / 148(64 \%)$ of respondents would consider dexmedetomidine if evidence suggested it was effective at least $80 \%$ of the time. Important perceived barriers to dexmedetomidine included inadequate personal (114/145, 79\%) and nursing (109/145, 75\%) experience, lack of access $(60 / 145,41 \%)$, prolonged time to sedation $(53 / 145,37 \%)$ and recovery $(44 / 145,30 \%)$ (Table 5). Lack of evidence was identified as a barrier by $24 / 145$ (17\%) of respondents and 16/145 (11\%) believed dexmedetomidine to be cost-prohibitive.

\section{Discussion}

\section{Interpretation}

Our national survey found that most Canadian pediatric emergency providers believed that at least a quarter of young children require physical restraint for suture repair and would provide anxiolysis. Most would provide intranasal benzodiazepines. However, given the lack of consistent efficacy of intranasal midazolam [6-8], our results suggest that future research should explore more effective anxiolytic strategies for children undergoing laceration repair and address barriers such as lack of provider experience, formulary access, and delayed management.

\section{Previous studies}

Most respondents (78\%) indicated they would use pharmacologic anxiolysis, most commonly (67\%) intranasal benzodiazepines such as midazolam. This is consistent with evidence that midazolam is the most frequently used anxiolytic for distressing procedures in children [7], including 
Table 4 Perceived barriers surrounding anxiolysis for laceration repair in the 3-year-old male featured in the vignette, $n=147$ (\%)

\begin{tabular}{|c|c|c|c|c|c|}
\hline & Strongly agree & Somewhat agree & $\begin{array}{l}\text { Neither } \\
\text { agree nor } \\
\text { disagree }\end{array}$ & Somewhat disagree & Strongly disagree \\
\hline $\begin{array}{l}\text { The time to produce effective anxiolysis/sedation will } \\
\text { delay management of the laceration repair }\end{array}$ & 6 & 32 & 9 & 29 & 23 \\
\hline $\begin{array}{l}\text { The time to recover from anxiolysis/sedation will } \\
\text { delay discharge of this patient }\end{array}$ & 10 & 39 & 12 & 23 & 14 \\
\hline $\begin{array}{l}\text { The route of administration (oral, intranasal, or intra- } \\
\text { venous) of an anxiolytic/sedative may cause more } \\
\text { discomfort than the laceration repair alone }\end{array}$ & 0 & 12 & 12 & 40 & 37 \\
\hline $\begin{array}{l}\text { The monitoring requirements are difficult in your } \\
\text { practice setting }\end{array}$ & 0.7 & 4 & 3 & 25 & 67 \\
\hline $\begin{array}{l}\text { The risks of providing an anxiolytic/sedative exceed } \\
\text { the benefit in laceration repair }\end{array}$ & 2 & 10 & 7 & 28 & 54 \\
\hline $\begin{array}{l}\text { Anxiolysis/sedation is not particularly effective for } \\
\text { children in this age group undergoing suture repair } \\
\text { of a laceration }\end{array}$ & 0 & 6 & 5 & 28 & 62 \\
\hline $\begin{array}{l}\text { Non-pharmacologic approaches (e.g., comfort meas- } \\
\text { ures) are sufficient for children in this age group } \\
\text { undergoing suture repair of a laceration }\end{array}$ & 4 & 16 & 15 & 31 & 34 \\
\hline $\begin{array}{l}\text { You are unfamiliar with anxiolysis/sedation options } \\
\text { for children in this age group undergoing suture } \\
\text { repair of laceration }\end{array}$ & 2 & 1 & 1 & 15 & 80 \\
\hline $\begin{array}{l}\text { Your practice setting does not support providing anxi- } \\
\text { olysis/sedation for laceration repair in this age group }\end{array}$ & 0 & 1 & 4 & 14 & 81 \\
\hline $\begin{array}{l}\text { Laceration repair using sutures will not cause signifi- } \\
\text { cant enough distress to warrant anxiolysis/sedation }\end{array}$ & $3(2)$ & $11(8)$ & $16(11)$ & $36(25)$ & $78(54)$ \\
\hline
\end{tabular}

laceration repair [18]. Intranasal midazolam administered via a mucosal atomizer device has a rapid onset of action; achieving $90 \%$ of its maximum concentration in 5-17 min [19], has a small intranasal volume requirement, and is widely available. Intranasal midazolam has also been studied extensively in children $[7,8,18]$, and all these factors may have influenced respondents' willingness to use it. Notably, trials have found conflicting results for oral or intranasal midazolam to facilitate suture repair in children [20-22]. A systematic review of 30 trials concluded there was insufficient high-quality evidence to determine whether midazolam produces more effective sedation than chloral hydrate and diazepam for therapeutic and diagnostic medical procedures [7]. In addition, intranasal midazolam is often noxious to the nasal mucosa and many children report a bitter taste in the mouth [9,23]. Not surprisingly, only $5 \%$ of respondents endorsed intranasal ketamine. Although it has an emerging role for analgesia in pediatric musculoskeletal injuries [24], there is little evidence of benefit in painful procedures [25] and effective doses often require large intranasal volumes. Nevertheless, intranasal drugs potentially offer a less distressing approach to medication delivery (compared to intravenous) and are suitable for children unable or unwilling to tolerate oral or inhaled therapy.
Almost two thirds of respondents had no experience with dexmedetomidine and indicated their comfort level was low, not entirely surprising given that dexmedetomidine is not standard practice in Canadian pediatric EDs. Data for dexmedetomidine in painful medical procedures in children are limited to a few trials $[14,26]$ and one study on initial positioning for suture repair [2]. Although dexmedetomidine appears to provide superior anxiolysis and is better tolerated than chloral hydrate, and midazolam for intravenous insertion [13, 26, 27] and dental procedures [14], uncertainty remains as to whether it facilitates suture repair [6]. Even though $64 \%$ of respondents would consider dexmedetomidine if there was evidence of benefit, $17 \%$ cited lack of evidence as a barrier. Prolonged time to effective sedation and recovery were reported by $37 \%$ and $30 \%$ of respondents, respectively. These are potentially important barriers because dexmedetomidine's onset and duration of sedation can be up to 31 and $92 \mathrm{~min}$, respectively [6], considerably longer than intranasal midazolam. Many sedative agents including oral and intranasal benzodiazepines, chloral hydrate, and dexmedetomidine are associated with length of stays ranging from 50 to $144 \mathrm{~min}$ [2, 21, 22, 28-30]. Lidocaine-epinephrine-tetracaine has an onset of action of 20-30 min [31], during which time, an anxiolytic can theoretically be administered, possibly reducing delays 
Table 5 Perceived barriers to using intranasal dexmedetomidine $(n=145)$

\begin{tabular}{ll}
\hline Barrier $^{1}$ & $n(\%)$ \\
\hline $\begin{array}{l}\text { Inadequate personal experience with intranasal dexmedeto- } \\
\text { midine }\end{array}$ & $114(79)$ \\
$\begin{array}{l}\text { Inadequate nursing experience with intranasal dexmedeto- } \\
\text { midine }\end{array}$ & $109(75)$ \\
Inadequate patient monitoring equipment & $10(7)$ \\
Inadequate physical space to provide anxiolysis/sedation & $11(8)$ \\
Lack of evidence supporting its effectiveness & $24(17)$ \\
Prolonged time to effective sedation & $53(37)$ \\
Prolonged time to recovery & $44(30)$ \\
Adverse effect profile & $28(19)$ \\
Patient unwillingness to receive anxiolysis/sedation & $7(5)$ \\
Caregiver unwillingness to receive anxiolysis/sedation & $13(9)$ \\
Nursing unwillingness to provide anxiolysis/sedation & $12(8)$ \\
Clinician unwillingness to provide anxiolysis/sedation & $18(12)$ \\
Inadequate access to intranasal atomizer devices & $9(6)$ \\
Inadequate access to dexmedetomidine in your practice & $60(41)$ \\
setting & \\
Cost prohibitive & $16(11)$ \\
Other sedative agents have a more rapid onset/offset of & $36(25)$ \\
action & \\
Other sedative agents have a superior safety profile & $11(8)$ \\
No perceived barriers & $6(4)$ \\
\hline
\end{tabular}

${ }^{1}$ The response options were presented from a drop-down list

in management. In centers that apply lidocaine-epinephrine-tetracaine at triage, anxiolytic administration in the ED can indeed contribute to delays in care. However, strategies employing best-evidence approaches to distress management have also been shown to decrease procedure time [32]. Nurse initiated protocols for drug administration have been used successfully to administer timely topical analgesia to manage needle-related pain in children [33]. Using a similar approach, future work should explore the feasibility of administering anxiolysis coincident with lidocaine-epinephrine-tetracaine to optimize timing of wound repair. Including intranasal midazolam as a trial arm may inspire practice change if dexmedetomidine is found to be superior. Only $11 \%$ of respondents cited cost as a barrier to dexmedetomidine, but this may reflect unfamiliarity. Even with the recent availability of a generic option, dexmedetomidine is much more expensive than midazolam. A $2 \mathrm{~mL}(100 \mathrm{mcg} /$ $\mathrm{mL}$ ) single-use vial of dexmedetomidine costs $\$ 45.20 \mathrm{CDN}$ versus $\$ 5.80 \mathrm{CDN}$ for a $10 \mathrm{~mL}(5 \mathrm{mg} / \mathrm{mL})$ single-use vial of midazolam [34].

\section{Strengths and limitations}

All respondents worked in tertiary care pediatric EDs, limiting the generalizability of our results. However, we may have also selected respondents who had more opportunities to be exposed to dexmedetomidine and therefore, greater ability to identify barriers. Social desirability bias is inherent to survey research [35] and may have led to over-reporting of willingness to provide anxiolysis. A medical record review may have provided more unbiased data related for practice patterns surrounding anxiolysis. We used only one vignette depicting a young child. Although younger children are more likely to display more distress than older children [36], practice patterns surrounding anxiolysis likely vary across age groups.

\section{Clinical implications}

Most pediatric ED clinicians believe that young children experience distress associated with laceration repair. However, very few have experience with intranasal dexmedetomidine for anxiolysis. Clinical adoption of intranasal dexmedetomidine will depend on rigorous evidence of benefit compared to the more frequently used benzodiazepines, comprehensive knowledge translation, and the exploration of strategies to minimize delays in care given its long duration of effect.

\section{Research implications}

Our findings suggest a need for studies exploring more effective strategies to reduce distress during laceration repair in children. Future research should incorporate protocols that minimize delays in management of lacerations.

\section{Conclusions}

This national survey found that most Canadian pediatric physicians believe that at least a quarter of young children require physical restraint for suture repair and would provide anxiolysis using intranasal benzodiazepines, despite inconsistent evidence of benefit. However, pediatric ED clinicians would be willing to use intranasal dexmedetomidine if research findings are favorable.

Supplementary Information The online version contains supplementary material available at https://doi.org/10.1007/s43678-021-00210-y.

Funding Department of Paediatrics Resident Research Grant. 


\section{References}

1. Spiro D, Zonfrillo M, Meckler F. Wounds. Pediatr Rev. 2010;31(8):326-34.

2. Neville DNW, Hayes KR, Ivan Y, McDowell ER, Pitetti RD. Double-blind randomized controlled trial of intranasal dexmedetomidine versus intranasal midazolam as anxiolysis prior to pediatric laceration repair in the emergency department. Acad Emerg Med. 2016;23:910-7.

3. Doyon-Trottier E, Doré-Bergeron MJ, Chauvin-Kimoff L, Baerg $\mathrm{K}$, Ali S. Managing pain and distress in children undergoing brief diagnostic and therapeutic procedures. Paediatr Child Health. 2019;24(8):509-21.

4. Fein JA, Zempsky WT, Cravero JP. Relief of pain and anxiety in pediatric patients in emergency medical systems. Pediatrics. 2012;130(5):e1391-405.

5. Miller JL, Capino AC, Thomas A, Couloures K, Johnson PN. Sedation and analgesia using medications delivered via the extravascular route in children undergoing laceration repair. J Pediatr Pharmacol Ther. 2018;23:72-83.

6. Poonai N, Spohn J, Vandermeer B, et al. Intranasal dexmedetomidine for anxiety-provoking procedures in children: a systematic review and meta-analysis. Pediatrics. 2020;145(1):e20191623.

7. Conway A, Rolley J, Sutherland JR. Midazolam for sedation before procedures. Cochrane Database Syst Rev. 2016;5:CD009491. https://doi.org/10.1002/14651858.CD009491.pub2.

8. Ashley PF, Chaudhary M, Lourenço-Matharu L. Sedation of children undergoing dental treatment. Cochrane Database Syst Rev. 2018;12(12):CD003877.

9. Klein EJ, Brown JC, Kobayashi A, Osincup D, Seidel K. A randomized clinical trial comparing oral, aerosolized intranasal, and aerosolized buccal midazolam. Ann Emerg Med. 2011;58:323-9.

10. Bar-Meir E, Zaslansky R, Regev E, Keidan I, Orenstein A, Winkler E. Nitrous oxide administered by the plastic surgeon for repair of facial lacerations in children in the emergency room. Plast Reconstr Surg. 2006;117(5):1571-5.

11. Sulton C, McCracken C, Simon HK, et al. Pediatric procedural sedation using dexmedetomidine: a report from the Pediatric Sedation Research Consortium. Hosp Pediatr. 2016;6(9):536-44.

12. Gupta A, Dalvi NP, Tendolkar BA. Comparison between intranasal dexmedetomidine and intranasal midazolam as premedication for brain magnetic resonance imaging in pediatric patients: a prospective randomized double blind trial. J Anaesthesiol Clin Pharmacol. 2017;33:236-40.

13. Ghai B, Jain K, Saxena AK, Bhatia N, Sodhi KS. Comparison of oral midazolam with intranasal dexmedetomidine premedication for children undergoing CT imaging: a randomized, double-blind, and controlled study. Pediatr Anesth. 2017;27:37-44.

14. Surendar MN, Pandey RK, Saksena AK, Kumar R, Chandra G. A comparative evaluation of intranasal dexmedetomidine, midazolam and ketamine for their sedative and analgesic properties: a triple blind randomized study. J Clin Pediatr Dent. 2014;38(3):255-61.

15. Dillman DA. Mail and Internet Surveys. 2nd Edition. John Wiley \& Sons Inc. (Hoboken, New Jersey). 2007.

16. Harris PA, Taylor R, Thielke R, Payne J, Gonzalez N, Conde JG. Research electronic data capture (REDCap) — a metadata-driven methodology and workflow process for providing translational research informatics support. J Biomed Inform. 2009;42(2):377-81.

17. Burns KE, Duffett M, Kho ME, et al. A guide for the design and conduct of self-administered surveys of clinicians. CMAJ. 2008;179(3):245-52.
18. Malia L, Laurich VM, Sturm JJ. Adverse events and satisfaction with use of intranasal midazolam for emergency department procedures in children. Am J Emerg Med. 2019;37(1):85-8.

19. Mellion SA, Bourne D, Brou L, et al. Evaluation clinical effectiveness and pharmacokinetics of atomized intranasal midazolam in children undergoing laceration repair. J Emerg Med. 2017;53(3):397-404.

20. Theroux MC, West DW, Corddry DH, et al. Efficacy of intranasal midazolam in facilitating suturing of lacerations in preschool children in the emergency department. Pediatrics. 1993;91(3):624-7.

21. Younge PA, Kendall JM. Sedation for children requiring wound repair: a randomised controlled double blind comparison of oral midazolam and oral ketamine. Emerg Med J. 2001;18:30-3.

22. Everitt IJ, Barnett P. Comparison of two benzodiazepines used for sedation of children undergoing suturing of a laceration in an emergency department. Pediatr Emer Care. 2002;18(2):72-4.

23. Kogan A, Katz J, Efrat R, et al. Premedication with midazolam in young children: a comparison of four routes of administration. Paediatr Anaesth. 2002;12:685-9.

24. Frey TM, Florin TA, Caruso M, Zhang N, Zhang Y, Mittiga MR. Effect of intranasal ketamine vs fentanyl on pain reduction for extremity injuries in children: the PRIME randomized clinical trial. JAMA Pediatr. 2019;173(2):140-6.

25. Poonai N, Canton K, Ali S, et al. Intranasal ketamine for procedural sedation and analgesia in children: a systematic review. PLOS ONE. 2017;12(3).

26. Xie Z, Shen W, Lin J, Xiao L, Liao M, Gan X. Sedation effects of intranasal dexmedetomidine delivered as sprays versus drops on pediatric response to venous cannulation. Am J Emerg Med. 2017;35:1126-30.

27. Qiao H, Xie Z, Jia J. Pediatric premedication: a double-blind randomized trial of dexmedetomidine or ketamine alone versus a combination of dexmedetomidine and ketamine. BMC Anaesth. 2017;17:158-65.

28. Cao Q, Lin Y, Xie Z, et al. Comparison of sedation by intranasal dexmedetomidine and oral chloral hydrate for pediatric ophthalmic examination. Pediatr Anesth. 2017;27(629-36).

29. Gan X, Lin H, Chen J, Lin Z, Lin Y, Chen W. Rescue sedation with intranasal dexmedetomidine for pediatric ophthalmic examination after chloral hydrate failure: a randomized controlled trial. Clin Ther. 2016;38(6):1522-9.

30. Miller J, Xue B, Hossain M, Zhang M-Z, Loepke A, Kurth D. Comparison of dexmedetomidine and chloral hydrate sedation for transthoracic echocardiography in infants and toddlers: a randomized clinical trial. Pediatr Anesth. 2016;26:266-72.

31. Kundu S, Achar S. Principles of Office Anesthesia: Part II. Topical Anesthesia. Am Fam Phys. 2002;66(1):99-102.

32. Baxter ALFR, Burke BL, Goldblatt SS, Isaacman DJ, Lawson ML. Local anesthetic and stylet styles: factors associated with resident lumbar puncture success. Pediatrics. 2006;117:876-81.

33. Friedrichsdorf SJ, Eull D, Weidner C, Postier A. A hospital-wide initiative to eliminate or reduce needle pain in children using lean methodology. Pain Rep. 2018;3:1-11.

34. Canadian Agency for Drugs and Technologies in Health. Dexmedetomidine for Sedation in the ICU or PICU: A Review of CostEffectiveness and Guidelines. Appendix 1. Cost Comparison of ICU Sedatives Ottawa, Ontario, Canada2014. https://www.ncbi. nlm.nih.gov/books/NBK268691/

35. Mindell JS, Coombs N, Stamatakis E. Measuring physical activity in children and adolescents for dietary surveys: practicalities, problems and pitfalls. Proc Nutr Soc. 2014;73(02):218-25.

36. Arts SE, Abu-Saad HH, Champion GD, et al. Age-related response to lidocaine-prilocaine (EMLA) emulsion and effect of music distraction on the pain of intravenous cannulation. Pediatrics. 1994;93:797-801. 


\section{Authors and Affiliations}

Kriti Kumar $^{1} \cdot$ Samina Ali $^{2} \cdot$ Vikram Sabhaney $^{3} \cdot$ Evelyne Trottier $^{4} \cdot$ Amy Drendel $^{5} \cdot$ Maala Bhatt $^{6} \cdot$ Leslie Boisvert $^{1}$. Naveen Poonai ${ }^{7,8}$ on behalf of Pediatric Emergency Research Canada

1 Department of Pediatrics, Schulich School of Medicine and Dentistry, Western University, London, ON, Canada

2 Department of Pediatrics, Faculty of Medicine and Dentistry, Women and Children's Health Research Institute, University of Alberta, Edmonton, AB, Canada

3 Department of Pediatrics, Faculty of Medicine, British Columbia Children's Hospital, University of British Columbia, Vancouver, BC, Canada

4 Département d'Urgence Pédiatrique, CHU Sainte-Justine, Faculté de Médecine, Université de Montréal, Montréal, QC, Canada
Department of Pediatrics, Children's Hospital of Wisconsin, Milwaukee, WI, USA

6 Department of Pediatrics, Children's Hospital of Eastern Ontario, Ottawa, ON, Canada

7 Departments of Paediatrics, Internal Medicine, Epidemiology and Biostatistics, Schulich School of Medicine and Dentistry, Western University, 800 Commissioners Road East, London, ON N6A 2V5, Canada

8 Division of Pediatric Emergency Medicine, Children's Health Research Institute, London Health Sciences Centre, London, ON, Canada 